\title{
Dynamics of Social Media Metrics and Firm Equity Value
}

\author{
Imran Khan $^{1 *}$, Dr Han Dongping ${ }^{2}$, Zeeshan Ahmad ${ }^{3}$, Majid Lateef ${ }^{4}$ and Po \\ Bunnika $^{5}$ \\ ${ }^{1}$ PhD Scholar at School of Management, Harbin Institute of Technology, China; \\ Lecturer at Department of Management Sciences, The Islamia University of \\ Bahawalpur, Pakistan \\ ${ }^{2}$ Professor at School of Management, Harbin Institute of Technology, China \\ ${ }^{3} \mathrm{PhD}$ Scholar at College of Economics and Management, Northeast Agricultural \\ University, China \\ ${ }^{4}$ PhD Scholar at College of Economics and Management, Northeast Forestry \\ University, China \\ ${ }^{5}$ PhD Scholar at College of Economics and Management, Northeast Agricultural \\ University, China \\ ${ }^{1}$ Imrankhan_lec@hotmail.com, ${ }^{2}$ handongping@hit.edu.cn, ${ }^{3}$ zeeshanahamd0o@yah \\ oo.com, ${ }^{4}$ majidonweb@foxmail.com, ${ }^{5}$ bunnika_po@yahoo.com
}

\begin{abstract}
Social media metrics in online environment provide a powerful source of customer feedback in predicting firm performance. Current study examines whether social media metrics specifically in terms of Facebook $(F B)$ and Twitter metrics, are related to stock market performance. Which of these metrics has the stronger relationship, and explores the dynamics of these relationships. The authors collected social media metrics data from official Facebook pages and Twitter accounts of three fast food companies over a period of six months. They developed multiple metrics of each social media platform and derive results using Vector Autoregressive time-series models to assess the immediate and longterm relationship between social media metrics and stock market performance of the firms in terms of abnormal returns and idiosyncratic risk. Results indicate that FB metrics are significant leading indicators of firm equity value. Interestingly, Twitter metrics, as compared to FB metrics, are found to have significant but substantially weaker predictive relationship with organizational equity value. Collectively, current research extends new visions for organizational top executives and investors with respect to organizational equity valuation and the social media power transformation.
\end{abstract}

Keywords: social media metrics; firm equity value; Facebook; Twitter; social media marketing

\section{Introduction}

Social media marketing is also known as word-of-mouth marketing, buzz, viral and guerrilla marketing [1-2]. Social media tools are gaining popularity and these are part of regular operations of large sum of companies of all sizes: start-ups, small, medium and large corporations [3-6]. Companies using social media technologies, outperformed than their competitors not using these technologies and have achieved benefits of low cost and higher efficiency [7]. Companies are capitalizing their financial value through social media transformation in business because of the increasing popularity of social media among consumers [8]. This transformation can be in the form of customer relationship

${ }^{*}$ Corresponding Author 
management, corporate business processes and brand building for executives. Quantitative analysis of social media's financial value to the organization is crucial to justify the investment of significant resources in it [9]. Social media enables the organization to utilize rich information about consumer decisions with the help of information technology advancement which is inaccessible through traditional media. Furthermore, social media has unprecedented the speed of content spread and continuously updating contents that provide the primary information to organizations and their investors. Social media contents are the source of timely assessment of organization's products and brands while sales information is not available at this frequency. Thus, social media not only enables the investors to perform sentiment analysis of firm's contents but also to analyse the brand performance and its future value. As we discussed that social media can arm the investors with unceasingly updating information about the future performance of their prospective firm, it may be the most important predictor of firm equity value function.

Prior literature of finance provides evidence that investors depend on information acquired from internet [10], search attention [11], customer feedback [12], print media [13], and online chatters [14]. Social media is exceptional in terms of generating contents, sharing and spreading information virally. Because of these distinctive features, social contagion effect is generated that determines the incomparable speed of digital information diffusion [15].

Previous researches evaluated the association among products sales and digital user metrics e.g.,[16-17], while current research reveal new insights by highlights the predictive association between firm equity value and social media metrics. Firm equity value is an ultimate tool to measure the market performance of the firm. Executive's compensation and their career projections are directly depending on firm stock prices so they are a lot concerned to it. According to [18-19], shareholder wealth and financial performance of the firm can be measured through firm equity value. While sales revenue cannot represent shareholder wealth but it is prime indicator of top line performance. Firm equity value is compatible with social media metrics as it can be recorded and monitored at a high frequency than sales revenue. Moreover, stock market can respond faster to the social media contents which are diffused virtually than actual product sales. Because of this dynamics executives concerned about shareholder wealth beyond and over the sales. By keeping in mind that shareholder wealth determined by two moments of stock prices (risk and return), we measure firm equity value with both moments. Whereas risk is associated with the capital cost, corporate bankruptcy and wealth vulnerability of shareholder and return apprehends the fluctuation in shareholders wealth [12-14]. Because of this simultaneous linkage between social media and two moments of stock prices (risk and return), we highlight the new mechanism in evaluation of predictive relationship between frim equity value and social media metrics. Current research contributes to the literature by focusing on multiple investigation sources of social media (Facebook and Twitter) as previous researches are limited to single source. Beyond level- and valencebased measures, current study utilize the consistent volume-based approach (number of posts, FB engagement, post interaction, number of fan posts, number of tweets, Twitter engagement, tweet interaction and retweets) to validate the predictive value of social media metrics.

Another contribution of current research is that this research models the long-term predictive value of social media metrics with vector autoregressive model (VAR)- a flexible time-series technique to estimate long-term, accumulated social media metrics effects and evaluate whether such effect unfold nonmonotonically over time [12-20]. This type of modelling is a paramount for social media strategies that are monitoring dynamically and evaluate the digital media system effectiveness over time. 


\section{Theoretical Background and Research Questions \\ 2.1. Social Media Metrics and Equity Value of Firm}

Efficient market hypothesis in finance literature demonstrates that market expectation is sensitive to new information that can move a firm's stock price [21-22]. Information asymmetry in stock market is also suggested in finance literature [23-24]. Sensible investors seek additional information sources in addition to the traditional sources to determine the firm equity value. These traditional sources of information include new product announcements, product quality, $R \& D$, profits, and other assets [19]. These sources are available at monthly or quarterly bases. Web 2.0 applications and social media are profoundly altering the way of connections between customers and organizations [25]. Social media popularity and its convoying user generated contents can be protuberant source of fresh information for managers and investors regarding future performance of the firm [26]. Social media is an important source of information as literature supports the belief how investors and consumers notice what other users share through social media [9, 19]. Less informed customers or customers with indecision of their product choice get influence from wisdom of crowd [14]. Customer's feedback and recommendations are accurately and truthfully recorded by the internet technologies that are altruistic intentions of consumers [27]. So that user generated contents on social media like satisfaction and positive word-of-mouth are perceived more reliable by the customers and investors [28].

Customer satisfaction also has positive impact on organizational equity value [29]. Branding literature unhide that increase in customer-based brand ratings can increase the returns and reduce risk of the firm that leads to increase in shareholder's value [30]. Literature proves that intangible assets and IT applications can enforce positive impact on firm market value [31]. Furthermore, research suggests that widespread social media assignation should hold more IT intangible assets and stouter predictions of future equity value than the foils with minimal or low social media engagement [32]. Hence, we have the following:

Research Question 1 (RQ1). Social media metrics, Facebook and Tweeter engagement in particular, have a significant predictive relationship with firm equity value.

\subsection{Which Social Media (Facebook or Twitter) is a Stronger Indicator in Predicting Firm Equity Value?}

Search engine and web pages were the sources of information for consumers before social media emergence. Organizations can interact with customers in limited intense through mass communication (web ads) or asynchronous media like email [25]. Previously consumers had partial ability to influence and observe the purchase decisions of others.

Social media metrics are more socially contagious than internet searches and web traffic, and social media plays a vital role in influencing responses of investors and diffusion of information [15]. Social media contents are more visible and can be read and shared among consumers with easy online access [14]. Finance literature proves that more visible information attains asymmetric response of investors [24]. Furthermore, social media metrics generate higher consumer engagement and occupies a larger online time of users [25]. Prior researches prove that consumers, those spending more time and effort in social media, interaction in terms of writing post, comments and liking of brand pages, ostensibly have more brand commitment and loyalty [14]. Thus, the above discussion suggest that social media metrics have a predictive relationship with firm equity value. Current research explore that among the two social media metrics (Facebook metrics and Twitter metrics), who has a stronger indicator in predicting firm equity value. Hence, we have the following:

Research Question 2 (RQ2). Which social media metric (Facebook metrics or Twitter metrics) has a stronger predictive relationship with firm equity value. 


\section{Data and Measure}

In current study, we selected the fast food industry as our research context for several reasons. First, consumers of fast food industry are more likely to participate in and be influenced by varies digital media. Second, organizations in this industry leverage social media to promote products and engage customers online as $57 \%$ of consumers view a restaurants website before dining there. Third, global fast food industry sales increased over two trillion dollars and 13 million employees are associated with this industry [33].

Within the fast food industry we selected three firms that serve the consumer markets to ensure the availability of social media contents and reviews. The selected companies are among the top 5 players of the industry, generating more than $70 \%$ of United States market share.

The daily data were collected from the official Facebook fan pages and twitter account of the companies during the period of July 1, 2014 to December 31, 2014. The collected data set contains 384 observations, representing the 3 companies over 128 trading days. The descriptive statistics of the firms are available in Table 1.

Table 1. Firm Wise Descriptive Statistics

\begin{tabular}{|c|c|c|c|c|c|c|c|c|c|c|}
\hline & $\begin{array}{l}\text { RTR } \\
\mathrm{N}\end{array}$ & FPST & FBE & PINT & PST & RTWT & RSK & TWT & TWTE & TWTI \\
\hline Dominos & $\begin{array}{l}0.13 \\
(0.012 \\
)\end{array}$ & $\begin{array}{l}35.64 \\
(35.55)\end{array}$ & $\begin{array}{l}0.0087 \\
(0.005 \\
7)\end{array}$ & $\begin{array}{l}0.858 \\
(0.007 \\
1)\end{array}$ & $\begin{array}{l}1.15 \\
(0.58 \\
)^{2}\end{array}$ & $\begin{array}{l}235.98 \\
(222.3 \\
3)\end{array}$ & $\begin{array}{l}0.96 \\
(0.08)\end{array}$ & $\begin{array}{l}127.6 \\
5 \\
(40.12 \\
)\end{array}$ & $\begin{array}{l}0.0912 \\
(0.066 \\
4)\end{array}$ & $\begin{array}{l}0.0007 \\
(0.000 \\
5)\end{array}$ \\
\hline KFC & $\begin{array}{l}-0.06 \\
(0.011 \\
) \\
\end{array}$ & $\begin{array}{l}2538.52 \\
(1374.6 \\
5)\end{array}$ & $\begin{array}{l}0.016 \\
(0.007 \\
1) \\
\end{array}$ & $\begin{array}{l}0.0266 \\
(0.009 \\
9) \\
\end{array}$ & $\begin{array}{l}0.5 \\
(0.58 \\
\end{array}$ & $\begin{array}{l}564.7 \\
(191.2 \\
6) \\
\end{array}$ & $\begin{array}{l}1.132 \\
4 \\
(0.07) \\
\end{array}$ & $\begin{array}{l}26.27 \\
(20.92 \\
\end{array}$ & $\begin{array}{l}0.0632 \\
(0.099 \\
1) \\
\end{array}$ & $\begin{array}{l}0.0204 \\
(0.005 \\
6) \\
\end{array}$ \\
\hline $\begin{array}{l}\text { McDonal } \\
\text { d }\end{array}$ & $\begin{array}{l}-0.03 \\
(0.007 \\
) \\
\end{array}$ & $\begin{array}{l}12.48 \\
(7.14) \\
\end{array}$ & $\begin{array}{l}0.0637 \\
(0.060 \\
2) \\
\end{array}$ & $\begin{array}{l}0.2275 \\
(0.101 \\
0) \\
\end{array}$ & $\begin{array}{l}0.79 \\
(0.68 \\
) \\
\end{array}$ & $\begin{array}{l}683.59 \\
(363.7 \\
4) \\
\end{array}$ & $\begin{array}{l}0.611 \\
2 \\
(0.02) \\
\end{array}$ & $\begin{array}{l}55.26 \\
(48.32 \\
) \\
\end{array}$ & $\begin{array}{l}0.0401 \\
(0.060 \\
8) \\
\end{array}$ & $\begin{array}{l}0.0032 \\
(0.001 \\
8) \\
\end{array}$ \\
\hline
\end{tabular}

where RTRN $=$ firm return, FPST $=$ fan posts, FBE $=$ Facebook engagement, $\mathrm{PINT}=$ post interaction, PST $=$ number of posts, RTWT $=$ retweets, RSK $=$ risk, TWT = number of tweets, TWTE $=$ Twitter engagement, TWTI = tweet interaction

Note: Standard deviation in parenthesis

\subsection{Data and Measures for Firm Equity Value}

Firm equity value can be measured through two different methods: stock risk and return as suggested by the literature of information system, finance and marketing [1234]. According to finance literature return/abnormal return is equity value of firm yonder what is expected by the average capital market via the extended Fama-French model [3536]. Volatility or vulnerability of organization equity value is denoted as risk or idiosyncratic risk. It can be measured as the extended Fama-French model residual's standard deviation that can measure the $80 \%$ of the total firm risk [37].

$R_{i t}-R_{f t}=\beta_{0 i}+\beta_{1 i}\left(R_{m t}-R_{f t}\right)+\beta_{2 i} S M B_{t}+\beta_{3 i} H M L_{t}+\beta_{4 i} M O M_{t}+e_{i t}$

Where Rit $=$ returns for firm $\mathrm{i}$ on time $\mathrm{t}, \mathrm{Rmt}=$ average market returns, $\mathrm{Rft}=$ risk-free rate, $\mathrm{SMBt}=$ size effects, $\mathrm{HMLt}=$ value effects, $\mathrm{MOMt}=$ Carhart's momentum effects, $\beta 0 \mathrm{i}=$ the intercept, and eit= the model residual1. The first model was ran for a 250 trading days rolling window prior to the target day.

Abnormal returns (ARit) can be calculated as the difference between the observed returns and the expected returns:

\footnotetext{
${ }^{1}$ Data for Fama-French factors and momentum $\left(\mathrm{R}_{\mathrm{mt}}, \mathrm{R}_{\mathrm{ft}}, \mathrm{HML}_{\mathbf{t}}, \mathrm{SMB}_{\mathrm{t}}\right.$, and $\mathrm{MOM}_{\mathrm{t}}$ are available at http://mba.tuck.dartmouth.edu/pages/faculty/ken.french/data_library.html.
} 


$$
A R_{i t}=\left(R_{i t}-R_{f t}\right)-\left(\hat{\beta}_{O i}+\hat{\beta}_{1 i}\left(R_{m t}-R_{f t}\right)+\hat{\beta}_{2 i} S M B_{t}+\hat{\beta}_{3 i} H M L_{t}+\hat{\beta}_{4 i} M O M_{t}\right)
$$

Risk is the standard deviation of the model residuals. The average range of firm daily returns lies between $-0.06 \%$ to $0.13 \%$ and the average value of daily stock risk ranges from 0.02 to 1.13 .

\subsection{Data and Measure of the Social Media Metrics}

We collected the data for Facebook metrics from the brand fan page of each firm. We designed software agents in Python language to crawl data from the fan pages of each firm on Facebook and timeline of Twitter. This program crawling data from Facebook fan pages of each firm about moderator posts, fan posts, likes, comments, shares with date and time. Data crawling from the Twitter was done based on firm's official account names and hash tags about tweets, retweets, mentions, replies and likes. It is widely applied in information science literature to use data crawler with an automated software from public websites [26-38].

3.2.1. Facebook Metrics : Number of posts are the total posts posted by relevant firm moderator and fan post are the posts posted by fans of the relevant company on fan page on a given day. Post interaction shows the brand fans reaction to the moderator post in terms of likes, comments and shares. Facebook engagement is the overall reactions of brand fans to the moderator all posts in terms of likes, comments, shares and fan posts on a given day [39].

3.2.2. Twitter Metrics: Twitter engagement is the sum of the four components including replies, mentions, retweets and likes of moderator all tweets in a given day. Retweets are the number of times users share tweets of firm moderator with their followers in a given day. Number of tweets are the total number of tweets posted by firm on given day and tweet interaction is the reaction of users to a specific firm's tweet in terms of replies, mentions, retweets and likes on a given day.

\subsection{Data for Exogenous Control Variables}

This research follows firm valuation models, broadly used in marketing, accounting and IS research [14], [40-41], and certain exogenous variables are kept as control variables. These variables include, revenue (sales) for firm equity value calculation, firm size (firm's total assets), liquidity (current ratio) financial leverage (ratio of long-term book debt to total assets), and ROA (ratio of the firm operating income to book value of total asset). Data of these variables is extracted from the financial statements of the firms in the given period. These variable data is available on quarterly bases but social media data is collected on daily bases, authors adopt the VAR-bootstrapping scheme as a remedy, which use 5000 simulated databases to generate the value of those variables for each observed day [12-42].

\section{VAR Model Specification}

Vector Autoregressive, a time series technique, is employed to evaluate the feedback and dynamic interactions effects [12-20]. We selected this approach for several reasons. First, with the help of this model we can predict the direct effect of firm equity value, by tracking, not only immediate but also the long-term cumulative effects of social media metric. Second, it accounts for biases such as reversed causality, auto correlation and endogeneity. Third, with the help of this model we can capture the complex feedback loops like feedback effect that is firm equity value's reverse impact on future social media metrics. So that this model can build an overall complex chained effects in predicting social media metrics. Following steps are applied to each firm separately in empirically 
analysing this VAR model (Table A1 in Appendix). Recent researchers have applied VAR model in IS, finance and marketing research areas [20-43].

\subsection{Model Specification on the Predictive Values of Social Media Metrics}

Ten equation VAR model is estimated in which endogenous variables are Facebook metrics (Facebook engagement, number of posts, post interaction and fan posts), Twitter metrics (Twitter engagement, number of tweets, tweet interaction and retweets) and firm equity value metrics (risk and return). We also have exogenous control variables including firm size, liquidity, financial leverage, ROA and revenue. The specification of the VAR model is as under:

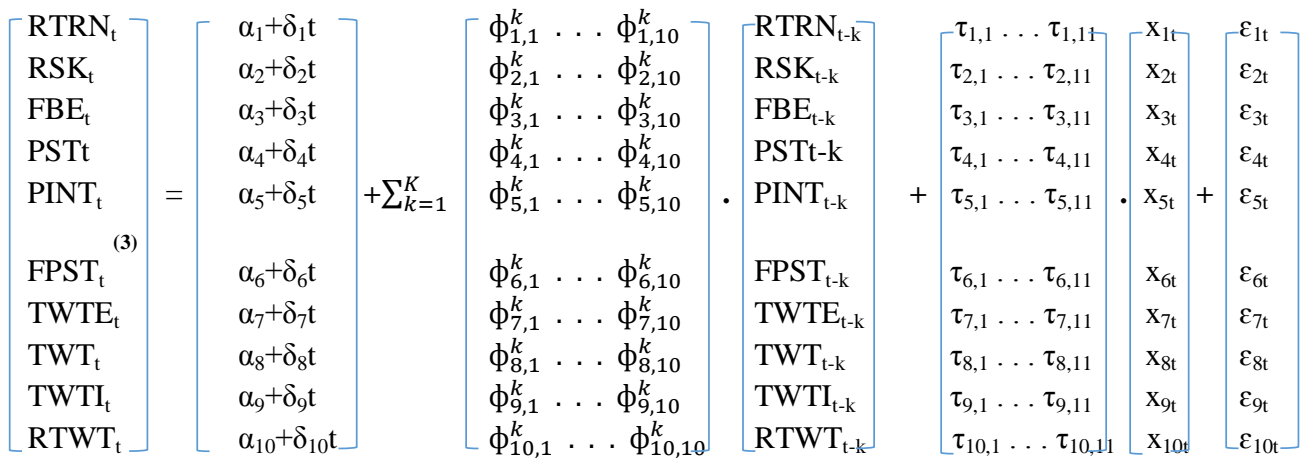

where $R T R N=$ firm return, $R S K=$ risk, $F B E=$ Facebook engagement, $P S T=$ number of posts, $P I N T=$ post interaction, $F P S T=$ fan posts, $T W T E=$ Twitter engagement, $T W T=$ number of tweets, $T W T I=$ tweet interaction, $R T W T=$ retweets, $t=$ time, $\alpha_{i}(i=1,2,3 \ldots, 10)$ $=$ constant $, \delta_{i}, \phi_{i j}, \tau_{i, l}(i, j=1,2,3, \ldots, 10, l=1,2,3, \ldots, 11)=$ coefficients, $k=$ lag length, $x_{i}(i$ $=1,2,3, \ldots, 11)=$ an exogenous variable, and $\varepsilon_{i}(i=1,2,3, \ldots, 10)=$ white-noise residual.

We use Schwartz's Bayesian information criterion (SC) and Akaike information criterion (AIC) for lag order selection in VAR model. We select the optimal lag order two with minimum value of SC and AIC by allowing various lag lengths in model [20-44] (Table A2 in Appendix). We test assumption of VAR residuals such as omission-ofvariables bias, portmanteau autocorrelation, multivariate normality and white heteroskedasticity test (Table A3-A5 in Appendix). No violations of these assumptions suggested by the results at $95 \%$ confidence level.

\subsection{Short- and Long-term Predictive Values of Social Media Metrics}

In the second step, generalized impulse response functions (GIRFs) was generated through estimated parameters $\phi_{i j}^{k}$ of full VAR model with $\psi_{i j}(\mathrm{t})$, which can measure the absolute effects of one unit of unexpected change in social media metric $i$ on organizational value metric $j$ at time $t$ [45]. Monte Carlo simulation with 5000 runs was used to drive standard errors for statistical significance testing of parameters at $5 \%$ level $(\mathrm{p}=0.05)$. Note that an orthogonal transformation was applied to correct the bias of whitenoise residuals that can correlate contemporaneously and produce ambiguous results (Luo 2009). Each GIRF generate multiple summary statistics: first, short-term and immediate predictive value; and second, long-term, total cumulative value that combines all effects across "dust-settling" periods.

\subsection{Risk and Return Variance Explained by Social Media Metrics}

Generalized forecast error variance decomposition (GFEVD) estimates were derived based on VAR parameters to evaluate which social media metric explain more or less variance of firm equity value in a systemic model. GFEVD measure the relative 
predictive strength of individual metric like a dynamic $\mathrm{R}^{2}$, without causal order assumption [45]. Following are the mathematical notation of GFEVD estimates:

$\theta_{i j}(t)=\frac{\sum_{k=0}^{t}\left(\psi_{i j}(k)\right)^{2}}{\sum_{k=0}^{t} \sum_{j=0}^{m}\left(\psi_{i j}(t)\right)^{2}}, i, j=1, \ldots, m$.

All of the firm equity value error variance to all endogenous variables were attributed by GFEVD. Thus, it can highlight the relative predictive value of Facebook metrics versus Twitter metrics. GFEVD in 20 days was used in establishment of this relative values of endogenous variables for the reduction in sensitivity to short-term fluctuation [14]. Standard errors were obtained through Monte Carlo simulation with 5000 runs for the establishment of GFEVD estimates significance $(\mathrm{p}=0.05)$ (Luo 2009).

\section{Findings}

\subsection{Variable Stationarity in Time Series}

VAR model estimation starts with checking of variables stationarity with unit-root tests. It means that although endogenous variable's unexpected change in VAR can bring variations over time but its effect disperse ultimately. And then, endogenous variables revert back to deterministic pattern (mean + shift + trend) without a permanent regime shift. Stationary variables have finite and time invariant variance. We checked stationarity of variables through augmented Dickey Fuller (ADF) [45]. The result of ADF test was less than critical value -2.89 for almost all metrics across firms and can reject the null hypothesis of a unit root $(p=0.05)$, except for all firms Facebook engagement and Risk series, two firm's fan post series and one firm's number of tweets series. We thus use the first differences for these metrics. As shown in Table 2, the ADF test results suggest that the variable series do not cointegrate in equilibrium as the corrected data series range from -3.78 to -16.07 [46].

Table 2 Endogenous Variables Stationarity Test

\begin{tabular}{|l|l|l|l|l|l|l|l|l|l|l|}
\hline & FBE & TWTE & PST & TWT & TWTI & PINT & FPST & RTWT & RTRN & RSK \\
\hline KFC & -11.67 & -12.62 & -5.29 & -5.00 & -7.78 & -12.13 & -3.78 & -11.78 & -10.80 & -9.30 \\
\hline Dominos & -16.07 & -10.53 & -9.54 & -7.32 & -9.83 & -8.00 & -16.72 & -11.07 & -11.97 & -14.17 \\
\hline McDonalds & -8.92 & -12.11 & -12.13 & -9.06 & -6.00 & -8.64 & -6.88 & -11.94 & -11.59 & -11.47 \\
\hline
\end{tabular}

Note: Critical value of ADF is -2.89 with $5 \%$ confidence level.

\subsection{Granger Causality Test}

Following [14-43], we apply Granger Causality test [47] and results are reported in Table 3. Our findings propose that Facebook metrics have temporal-based significant causal relationship with equity value of firm. Almost all Facebook metrics Granger cause significantly to equity value of firm. Facebook engagement, number of posts, fan posts and post interaction Granger cause stock risk ( $\mathrm{p}=0.01,0.02,0.02$ and 0.03$)$. Moreover, Facebook engagement and fan post cause firm stock return $(\mathrm{p}=0.01$ and 0.02$)$. From stock return to Facebook metrics reverse feedback is not significant, although stock risk is found to significantly Granger cause post interaction $(\mathrm{p}=0.05)$. These findings validate the temporal predictive relationship between Facebook metrics and firm equity value, providing evidence for RQ1. 
Table 3. Granger Causality Test Results Summary

\begin{tabular}{|l|c|c|}
\hline & Return & $\Delta$ Risk \\
\hline Facebook Engagement & $0.01^{*}$ & $0.01^{*}$ \\
\hline Fan Posts & $0.02^{*}$ & $0.02^{*}$ \\
\hline Post Interaction & 0.19 & $0.03^{*}$ \\
\hline Number of Posts & 0.28 & $0.02^{*}$ \\
\hline Retweets & 0.23 & 0.46 \\
\hline Number of Tweets & $0.04^{*}$ & 0.53 \\
\hline Twitter Engagement & $0.03^{*}$ & $0.02^{*}$ \\
\hline Tweet Interaction & 0.41 & 0.23 \\
\hline
\end{tabular}

Note: The estimates of the Granger causality are the mean of the $p$-values of the joint Wald statistics.

${ }^{*} p<0.05$.

Related to Twitter metrics, Twitter engagement significantly Granger causes both risk and return ( $p=0.02$ and 0.03 respectively). Moreover, number of tweets significantly Granger causes return $(p=0.04)$. From stock return to Twitter metrics reverse feedback is not significant, although stock risk is found Granger cause significantly with tweet interaction $(\mathrm{p}=0.03)$.

\subsection{Short- and Long-Term Predictive Values of Social Media Metrics}

Cumulative/immediate impulsive response elasticities from the GIRFs results are reposted in Table 4 . The elasticity results magnitude identify the change in basis point of stock return where one base point equals to one hundredth of a percentage. Moreover, stock risk percentage is in response to one unit of unexpected change in social media metrics. These findings mostly support the RQs. Results details are discussed below.

Table 4. Impulse Responses of Firm Equity Value to Social Media Metrics

\begin{tabular}{|l|c|c|c|c|}
\hline & \multicolumn{2}{|c|}{ Return } & \multicolumn{2}{c|}{ Risk } \\
\hline & Immediate & Accumulative & Immediate & Accumulative \\
\hline Facebook Metrics & & & & \\
\hline Facebook Engagement & $1.79^{* *}$ & $3.49^{* *}$ & $-0.031^{* *}$ & $-0.089^{*}$ \\
\hline Number of Posts & $0.87^{*}$ & 1.86 & $-0.014^{*}$ & $-0.054^{*}$ \\
\hline Post Interaction & $0.69^{* *}$ & $2.98^{* *}$ & $-0.022^{* *}$ & $-0.048^{*}$ \\
\hline Fan Posts & 0.43 & $2.60^{*}$ & $-0.012^{*}$ & 0.052 \\
\hline Twitter Metrics & & & & \\
\hline Twitter Engagement & $1.24^{*}$ & $3.05^{* *}$ & $-0.028^{*}$ & $-0.093^{* *}$ \\
\hline Number of Tweets & 0.22 & $2.64^{*}$ & $-0.017^{*}$ & 0.042 \\
\hline Tweet Interaction & 0.21 & 1.90 & 0.011 & $-0.045^{*}$ \\
\hline Retweets & 0.16 & $2.76^{*}$ & $-0.03^{*}$ & -0.091 \\
\hline
\end{tabular}

Note: Risk coefficients are in percentage and return coefficients are in basis points where 1 basis point is equals to one hundredth of a percentage.

${ }^{*} p<0.05,{ }^{* *} p<0.01$ 
5.3.1. Facebook Metrics: Table 4, showed that Facebook metrics in term of Facebook engagement have a significantly positive predictive relationship with firm return for both short- and long-terms (1.79 and 3.49 base points, respectively, $p<0.01)$ and significantly shrink the both short- and long-term risk $(0.031 \%, \mathrm{p}<0.01$ and $0.089 \%, p<0.05$ respectively). It shows that an unexpected surge in Facebook engagement will predict an increase in daily stock return by 0.000179 and reduce intraday stock risk by 0.00031 in short-term. Number of posts have a significantly positive predictive relationship with firm return for short-terms $(0.87$ bases points, $p<0.05)$ and shrink significantly the both shortand long-term risk $(0.014 \%, p<0.05$ and $0.054 \%, p<0.05$ respectively). Post interaction has a significantly positive predictive relationship with firm return for both short- and long-terms ( 0.69 and 2.98 bases points, respectively, $p<0.01)$ and shrink significantly the both short- and long-term risk $(0.022 \%, p<0.01$ and $0.048 \%, p<0.05$ respectively). Fan posts have a significantly positive predictive relationship with firm return for long-terms ( 2.60 bases points, $p<0.05)$ and shrink significantly the short-term risk $(0.012 \%, p<0.05)$. Thus, the findings propose that Facebook metrics are significant leading indicators of firm equity value, providing evidence for RQ1.

5.3.2. Twitter Metrics: Results in Table 4, suggest that Twitter metrics in term of Twitter engagement have a significant positive predictive short- and long-term relationship with firm return (1.24 base point, $p<0.05,3.05$ bases point, $p<0.01$, respectively) and significantly shrink the both short- and long-term risk $(0.028 \%, p<0.05$ and $0.098 \%$, $\mathrm{p}<0.01$, respectively). Number of tweets have a long-term significant relationship with firm return (2.64 basis point, $p<0.05)$ and reduce significantly the short-term risk $(0.017 \%$, $p<0.05)$. Tweet interaction has reduced the long-term risk $(0.045 \%, p<0.05)$, though insignificant in short- and long-term return and short-term risk. Retweet has a long-term significant predictive relationship with firm return $(2.67$ basis point, $p<0.05)$ and significantly shrink the short-term risk $(0.03 \%, p<0.05)$.

These results provide strong evidence in support of RQ1, Facebook and Twitter metrics have a significant predictive relationship with equity value of firm. Remarkably, the results propose that Facebook engagement is at top in predicting boost in stock returns in long-term and Twitter engagement is at peak in reduction of long-term risk.

\subsection{Relative Strength of the Predictive Value of Facebook Versus Twitter Metrics}

Table 5, provides the variance decomposition of GFEVD result that is the relative strength of individual metric in explaining the firm equity value variance. All FB and Twitter metrics explain nontrivial variance portions. According to findings the order of FB engagement $(1.84 \%)$, number of posts $(1.63 \%)$, post interaction $(1.31 \%)$ and fan posts $(0.62 \%)$ in predicting firm returns in long-run. Moreover, the results support the order of FB engagement (1.91\%), post interaction $(1.80 \%)$, number of posts $(1.51 \%)$ and fan posts $(1.51 \%)$ in predicting firm risk in long-run. The results suggest the order of Twitter interaction $(1.60 \%)$, number of tweets $(0.96 \%)$, tweet engagement $(0.61 \%)$ and retweets $(0.49 \%)$ in predicting firm return in long-run. Also, the results suggest the order of Twitter engagement $(1.36 \%)$, number of tweets $(1.35 \%)$, retweets $(1.30 \%)$ and tweet interaction $(1.24 \%)$ in predicting firm risk in long-run. Total Facebook metrics account for a significantly higher proportion of the variance than total Twitter metrics $(5.41 \%$ versus $3.66 \%$ in return and $6.75 \%$ versus $5.25 \%$ in risk). Results in table 5 also suggest that these differences are statistically significant $(F=10.85, \mathrm{p}<0.05$ for return and $F=$ $13.45, \mathrm{p}<0.05$ for risk). So that these findings support RQ2, that FB metrics have stronger predictive value than the Twitter metrics. 


\section{Table 5. Variance Decomposition of Firm Equity Value as Explained by} Social Media Metrics

\begin{tabular}{|l|c|c|}
\hline Variance Explained by & Return (\%) & $\Delta$ Risk (\%) \\
\hline Fan Posts & 0.62 & 1.51 \\
\hline Facebook Engagement & 1.84 & 1.91 \\
\hline Post Interaction & 1.31 & 1.80 \\
\hline Number of Posts & 1.63 & 1.53 \\
\hline Total FB Metrics & 5.41 & 6.75 \\
\hline Retweets & 0.49 & 1.30 \\
\hline Number of Tweets & 0.96 & 1.35 \\
\hline Twitter Engagement & 0.61 & 1.36 \\
\hline Tweet Interaction & 1.60 & 1.24 \\
\hline Total Twitter Metrics & 3.66 & 5.25 \\
\hline F Statistics & $10.85^{*}$ & $13.45^{*}$ \\
\hline
\end{tabular}

\section{Discussion}

Current research was trying to evaluate the social media's predictive power and dynamics of relationship among social media metric and equity value of firm. The findings indicate that Facebook metrics are primary indicators of firm equity value (proved through Granger causality tests) and has a higher predictive value than Twitter metrics. Facebook engagement has the highest predictive strength for firm risks and returns. Twitter engagement also shows the significant predictive power for firm risks and returns. The findings of the current research proffer important and novel implications for the theoretical and managerial absorbers of social media.

\subsection{Theoretical and Managerial Implications}

The findings of current research significantly contribute to marketing, finance and IS literature. Social media enable firms to attain short-term as well as long-term predictive benefits associated with equity value of firm. Social media is a primary indicator of firm equity value and validate the investments in it and IT initiatives for transformations of firm and shareholder's value creation. Organizations should not consider social media investment as net cost. Therefore, current research adds to the IT productivity literature [40-48]. Specifically, our findings prove that investment in social media on increasing Facebook and Twitter engagement would be most fruitful in terms of organizational future risk and return. Moreover, increasing investment in enhancing the Facebook posts and tweets on Twitter are also effective in terms of organizational risk and return management. Notably investment on Facebook and Twitter metrics are important. So that, top management should prioritize and allot marketing communication budgets properly among numerous social media platforms according to the ability in predicted financial value for firm.

Moreover, current research is among the first researches to highlight the association among social media and business stock performances in consideration of Facebook and Twitter metrics among marketing, IS and financial literature. Disbursement of organization communication on social media can enhance advocacy of the investors or consumers, and thus, results in enhanced firm value and shrieked risk. The engagement of consumers in Facebook posts and Twitter tweets provide the factor of trust to the consumers and reduce negative valence on social media. Research proved that damages of negative valence affects faster than the positive valence benefits [43].

Marketing and finance research have discussed the relationship between traditional online media (e.g., Web traffic/search) and organizational performance [11] and [43-49]. 
We expended this research stream by identifying that social media is more powerful indicator of organizational performance. So that, social media metrics can equip firms with more effective measures of online engagement of consumer and brand buzz, as well as prospects of organizational equity value in the social media age.

We have used time-series models for the measurement of long-term and accumulative value of social media metrics. Focusing on only short-term value would neglect the enduring effects of these digital user metrics that under estimation has been prevented by our models. The decisive concern of top management in shareholder's value that we have used as benchmark for business performance.

Current research provide guidelines for managers in several ways. Social media enable organizations to utilize customer relationship and brand buzz for enhancement of organizational equity value. Until now, some managers are unaware about their digital communication strategy. Our findings support social media metrics as these metrics can effectively predict organizational risk and return not only in short-term but also in longterm.

Our results suggest that managers have to prioritize these metrics for the enduring long-term returns of their social media investment. Managers have to develop strategies to enhance customer engagement in social media specifically Facebook and Twitter to increase firm value and reduce risk.

\subsection{Limitations and Future Research}

The limitations of this research may provide avenues for future research. First, one possible limitation is the current research design cannot assure the causality of the predictive social media value. The possible solution is the field experiment, future research can be conducted on this issue. Second, the contents of social media used in current research as endogenous variables may vary in the level of trustworthiness. Manipulation of user-generated contents on the internet in very common [50]. The possible solution of this problem is to find a new extension to current study. The future researchers may consider brand performance outcomes such as brand feeling, recommendation and reputation among employees as well.

Third, to enhance the generalization of current research, future research can be conducted in more diverse industries such as healthcare, videos and book industries. Future research can be conducted to explore the relation among IT related metrics (e.g., electronic WOM, social media and network ties) and finance metrics (e.g., investor attention, venture financing, analyst recommendations and initial public offerings) to advance the burgeoning finance-IS interface [51].

\subsection{Conclusion}

In conclusion, current research provides support in literature on IS, marketing and finance in examination of predictive relation among firm equity value and social media metrics. Social media transform business organizations significantly and it is hoped that future research in these fields will establish more scientific time-series models in discovering of new insights into the organizational value of social media.

\section{Appendix}

Table A6. Overview of the Empirical Analysis Method

\begin{tabular}{|c|c|c|c|}
\hline \multirow{2}{*}{ Method } & \multicolumn{2}{|c|}{ Prior Studies in } & \multirow{2}{*}{ Purpose } \\
\cline { 2 - 3 } & $\begin{array}{c}\text { Econometr } \\
\text { ics }\end{array}$ & Marketing & \\
\hline $\begin{array}{c}\text { Unit root tests- Augmented } \\
\text { Dickey-Fuller (ADF) }\end{array}$ & $\begin{array}{c}\text { Enders } \\
2004\end{array}$ & $\begin{array}{c}\text { Dekimpe and } \\
\text { Hanssens 1999 }\end{array}$ & to check the statioanrity of each variable \\
\hline
\end{tabular}




\begin{tabular}{|c|c|c|l|}
\hline $\begin{array}{c}\text { Vector autoregressive model with } \\
\text { exogenous variables (VAR) }\end{array}$ & $\begin{array}{c}\text { Dekimpe and } \\
\text { hanssens 1999 }\end{array}$ & $\begin{array}{l}\text { to check the interaction of each variable } \\
\text { accounting for exogenous variables }\end{array}$ \\
\hline $\begin{array}{c}\text { Impulse response functions- } \\
\begin{array}{c}\text { Generalized impulse response } \\
\text { function (GIRF) }\end{array}\end{array}$ & $\begin{array}{c}\text { Enders } \\
2004\end{array}$ & $\begin{array}{c}\text { Srinivasa } \text { et. } \\
\text { al., 2010 }\end{array}$ & $\begin{array}{l}\text { to analyse the net performance responses of } \\
\text { each user metric impulses }\end{array}$ \\
\hline $\begin{array}{c}\text { Variance decomposition- Forecast } \\
\text { error variance decomposition }\end{array}$ & $\begin{array}{c}\text { Enders } \\
2004\end{array}$ & $\begin{array}{c}\text { Srinivasa } \text { et. } \\
\text { al., } 2010\end{array}$ & $\begin{array}{l}\text { to examine the role of social media metrics } \\
\text { in explaining firm performance }\end{array}$ \\
\hline
\end{tabular}

Table A7. Lag Selection Criteria

\begin{tabular}{|c|c|c|c|c|c|c|}
\hline & \multicolumn{2}{|c|}{ Dominos } & \multicolumn{2}{c|}{ KFC } & \multicolumn{2}{c|}{ McDonlads } \\
\hline Lag & AIC & SC & AIC & SC & AIC & SC \\
\hline 0 & -54.56247 & -50.2698 & -41.40376 & -38.71772 & -42.30584 & -37.40151 \\
\hline 1 & -55.04466 & -52.4618 & -41.28665 & $-41.17022^{*}$ & -42.96362 & -40.39468 \\
\hline 2 & $-56.53863^{*}$ & $-54.32767^{*}$ & $-46.15262^{*}$ & -38.48338 & $-43.23868^{*}$ & $-43.00514 *$ \\
\hline 3 & -54.78491 & -47.506 & -42.98077 & -35.74103 & -41.76485 & -34.52512 \\
\hline 4 & -54.68153 & -45.0546 & -42.64013 & -33.065 & -41.50173 & -31.9266 \\
\hline 5 & -54.43891 & -42.4639 & -43.04049 & -31.12996 & -41.55153 & -29.641 \\
\hline 6 & -54.35165 & -40.0286 & -43.62351 & -29.37758 & -41.45194 & -27.20602 \\
\hline 7 & -54.83587 & -38.1648 & -44.44158 & -27.86026 & -41.2407 & -24.65938 \\
\hline 8 & -55.20066 & -37.5195 & -43.38771 & -27.23589 & -42.00455 & -23.08783 \\
\hline
\end{tabular}

* indicates lag order selected by the criterion

AIC: Akaike information criterion

SC: Schwarz information criterion

Table A8. Multivariate Normality Tests

\begin{tabular}{|l|r|r|r|r|}
\hline Firm & Skewness statistic & p-value & Kurtosis statistic & p-value \\
\hline KFC & 0.7731 & 0.698 & 3.118505 & 0.5107 \\
\hline Dominos & 0.234354 & 0.2867 & 2.945986 & 0.5315 \\
\hline McDonlads & -0.701836 & 0.7366 & 3.44465 & 0.3102 \\
\hline
\end{tabular}

Note: These calculations are based on Lutkepohl (1993). The results of DoornikHansen (1994) and Jarque-Bera univariate tests (Lutkepohl 1993) are also similar. Results are tested at $5 \%$ levels.

Table A9. White Heteroskedasticity and Autocorrelation Tests

\begin{tabular}{|l|c|c|c|c|}
\hline \multirow{2}{*}{ Firm } & \multicolumn{2}{|c|}{ White Heteroskedasticity ${ }^{1}$} & \multicolumn{2}{c|}{ Autocorrelation Test $^{2}$} \\
\cline { 2 - 5 } & Chi-sq. & Prob. & LM-Stat & Prob. \\
\hline Dominos & 2165.193 & 0.6976 & 70.84094 & 0.988 \\
\hline McDonalds & 2231.583 & 0.3142 & 91.22186 & 0.7232 \\
\hline KFC & 2322.918 & 0.5206 & 91.81141 & 0.7082 \\
\hline
\end{tabular}

Note1: These statistics are tested at $5 \%$ levels

$\mathrm{HO}$ : The multivariate data generation process is not autoregressive conditional heteroskedastic.

Note2: H0: no residual autocorrelations up to specified lag length (10)

Table A10. Tests of Granger Causality

\begin{tabular}{|l|l|l|l|l|l|l|}
\hline & \multicolumn{2}{|c|}{ KFC } & \multicolumn{2}{c|}{ Dominos } & \multicolumn{2}{c|}{ McDonalds } \\
\hline & Return & Risk & Return & Risk & Return & Risk \\
\hline
\end{tabular}




\begin{tabular}{|l|c|c|c|c|c|c|} 
FAN_POSTS & $2.43^{*}$ & $2.77^{*}$ & $2.24^{*}$ & $2.20^{*}$ & $2.63^{*}$ & $6.92^{*}$ \\
\hline FB_EGMT & $3.09^{*}$ & $2.50^{*}$ & $3.19^{*}$ & $3.24^{*}$ & $3.13^{*}$ & $3.16^{*}$ \\
\hline POST_INTERACTION & 0.39 & $2.51^{*}$ & $2.36^{*}$ & $3.14^{*}$ & $2.72^{*}$ & $2.57^{*}$ \\
\hline POSTS & $2.50^{*}$ & $2.40^{*}$ & $3.03^{*}$ & $2.54^{*}$ & 0.08 & $2.85^{*}$ \\
\hline RETWEETS & $2.51^{*}$ & 0.02 & 0.68 & 0.5 & $2.89^{*}$ & $2.62^{*}$ \\
\hline TWEETS & 1.3 & $3.40^{*}$ & 0.13 & 0.13 & $2.38^{*}$ & 0.22 \\
\hline TWT_EGMT & $2.48^{*}$ & $2.24^{*}$ & $2.41^{*}$ & $2.71^{*}$ & $2.72^{*}$ & $3.04^{*}$ \\
\hline TWT_INTERACTION & $2.40^{*}$ & 0.23 & 0.65 & $2.54^{*}$ & 0.15 & $3.39^{*}$ \\
\hline
\end{tabular}

$* p<0.05$

\section{Acknowledgments}

The authors gratefully acknowledge the insightful proofreading from Mr. Ken Margel; valuable suggestions and comments from marketing colleagues (Dr Zafar Yaqoob, Tauqir Ahmed Ghauri, and Dr Muhammad Abdullah); IS colleagues (Dr Sohail, Akhtar Wahab, Umar Ajmal, and Tanawar Khan) and the participants of IS summer school at Harbin Institute of Technology.

\section{References}

[1] E. Rosen, "The anatomy of buzz revisited", Real-life lessons in Word-of-Mouth Marketing. Überarb. und erw. Aufl., New York: Crown Business, (2009).

[2] A. Sernovitz and S. Clester, "Word of mouth marketing: How smart companies get people talking", Kaplan Pub., (2009).

[3] S. H.Lee, D. DeWester and S. R. Park, "Web 2.0 and opportunities for small businesses", Service Business, vol. 2, no. 4, (2008), pp. 335-345.

[4] D. Osimo, "Web 2.0 in government: Why and how", Institute for Prospectice Technological Studies (IPTS), JRC, European Commission, EUR. 23358, (2008).

[5] S. J. Andriole, "Business impact of Web 2.0 technologies", Communications of the ACM, vol. 53, no. 12, (2010), pp. 67-79.

[6] J. Bell and S. Loane, "New-wave'global firms: web 2.0 and SME internationalisation", Journal of Marketing Management, vol. 26, no. (3-4), (2010), pp. 213-229.

[7] L. Harris and A. Rae, "Social networks: the future of marketing for small business", Journal of business strategy, vol. 30, no. 5, (2009), pp. 24-31.

[8] R. Divol, D. Edelman and H. Sarrazin, "Demystifying social media", McKinsey Quarterly, vol. 2, no. 12, (2012), pp. 66-77.

[9] P. C. Deans, "The impact of social media on C-level roles", MIS Quarterly Executive, vol. 10, no. 4, (2011), pp. 187-200.

[10] S. R. Das and M. Y. Chen, "Yahoo! for Amazon: Sentiment extraction from small talk on the web", Management Science, vol. 53, no. 9, (2007), pp. 1375-1388.

[11] Z. Da, J. Engelberg and P. Gao, "In search of attention", The Journal of Finance, vol. 66, no. 5, (2011), pp. 1461-1499.

[12] X. Luo, "Quantifying the long-term impact of negative word of mouth on cash flows and stock prices", Marketing Science, vol. 28, no. 1, (2009), pp. 148-165.

[13] P. C. Tetlock, "Giving content to investor sentiment: The role of media in the stock market", The Journal of Finance, vol. 62, no. 3, (2007), pp. 1139-1168.

[14] S. Tirunillai and G. J. Tellis, "Does chatter really matter? Dynamics of user-generated content and stock performance", Marketing Science, vol. 31, no. 2, (2012), pp. 198-215.

[15] S. Aral and D. Walker, "Creating social contagion through viral product design: A randomized trial of peer influence in networks", Management Science, vol. 57, no. 9, (2011), pp. 1623-1639.

[16] V. Dhar and E. A. Chang, "Does chatter matter? The impact of user-generated content on music sales". Journal of Interactive Marketing, vol. 23, no. 4, (2009), pp. 300-307.

[17] A. Ghose and S. Yang, "An empirical analysis of search engine advertising: Sponsored search in electronic markets", Management Science, vol. 55, no. 10, (2009), pp. 1605-1622.

[18] S. Dewan and F. Ren, "Risk and return of information technology initiatives: Evidence from electronic commerce announcements", Information Systems Research, vol. 18, no. 4, (2007), pp. 370-394.

[19] Y. Chen, Y. Liu and J. Zhang, "When do third-party product reviews affect firm value and what can firms do? The case of media critics and professional movie reviews", Journal of Marketing, vol. 76, no. 2, (2012), pp. 116-134. 
[20] G. Adomavicius, J. Bockstedt and A. Gupta, "Modeling Supply-Side Dynamics of IT Components, Products, and Infrastructure: An Empirical Analysis Using Vector Autoregression", Information Systems Research, vol. 23, no. 2, (2012), pp. 397-417.

[21] E. F. Fama, "Efficient capital markets: A review of theory and empirical work", The journal of Finance. vol. 25, no. 2, (1970), pp. 383-417.

[22] P. A. Samuelson, "Proof that properly anticipated prices fluctuate randomly". Industrial management review, vol. 6, no. 2, (1965), pp. 41-49.

[23] P. M. Healy and K. G. Palepu, "Information asymmetry, corporate disclosure, and the capital markets: A review of the empirical disclosure literature", Journal of accounting and economics, vol. 31, no. 1, (2001), pp. 405-440.

[24] D. Hirshleifer and S. H. Teoh, "Thought and behavior contagion in capital markets", Handbook Of Financial Markets: Dynamics And Evolution, Handbooks in Finance, (2009), pp. 1-46.

[25] J. Gallaugher and S. Ransbotham, "Social media and customer dialog management at Starbucks", MIS Quarterly Executive, vol. 9, no. 4, (2010), pp. 197-212.

[26] B. Gu, J. Park and P. Konana, "Research note-the impact of external word-of-mouth sources on retailer sales of high-involvement products", Information Systems Research, vol. 23, no. 1, (2012), pp. 182-196.

[27] C. Dellarocas and C. A. Wood, "The sound of silence in online feedback: Estimating trading risks in the presence of reporting bias", Management Science, vol. 54, no. 3, (2008), pp. 460-476.

[28] W. A. Hanson and K. Kalyanam, "Internet marketing \& e-commerce", Thomson/South-Western, (2007).

[29] X. Luo, C. Homburg and J. Wieseke, "Customer satisfaction, analyst stock recommendations, and firm value", Journal of Marketing Research, vol. 47, no. 6, (2010), pp. 1041-1058.

[30] N. A. Morgan and L. L. Rego, "The value of different customer satisfaction and loyalty metrics in predicting business performance", Marketing Science, vol. 25, no. 5, (2006), pp. 426-439.

[31] Z. P. Matolcsy, and A. Wyatt, "The association between technological conditions and the market value of equity", The Accounting Review, vol. 83, no. 2, (2008), pp. 479-518.

[32] A. Wyatt, "Accounting recognition of intangible assets: theory and evidence on economic determinants", The accounting review, vol. 80, no. 3, (2005), pp. 967-1003.

[33] Statisticsbrain, Available from: http://www.statisticbrain.com/restaurant-industry-statistics/_(2016).

[34] S. Srinivasan, and D. M. Hanssens, "Marketing and firm value: metrics, methods, findings, and future directions", Journal of Marketing Research, vol. 46, no. 3, (2009), pp. 293-312.

[35] E. F. Fama and K. R. French, "Common risk factors in the returns on stocks and bonds", Journal of financial economics, vol. 33, no. 1, (1993), pp. 3-56.

[36] E. F. Fama and K. R. French, "Multifactor explanations of asset pricing anomalies", The journal of finance, vol. 51, no. 1, (1996), pp. 55-84.

[37] A. Goyal, and P. Santa-Clara, "Idiosyncratic risk matters!", The Journal of Finance, vol. 58, no. 3, (2003), pp. $975-1008$.

[38] R. Aggarwal, "Blog, blogger, and the firm: Can negative employee posts lead to positive outcomes?", Information Systems Research, vol. 23, no. 2, (2012), pp. 306-322.

[39] Facebook-Developers. Available from: https://www.facebook.com/help/178043462360087, (2016).

[40] E. Brynjolfsson, L. M. Hitt and S. Yang, "Intangible assets: Computers and organizational capital", Brookings papers on economic activity, vol. 2002, no. 1, (2002), pp. 137-198.

[41] M. A. Ferreira and P. A. Laux, "Corporate governance, idiosyncratic risk, and information flow", The Journal of Finance, vol. 62, no. 2, (2007), pp. 951-989.

[42] M. Statman, S. Thorley and K. Vorkink, "Investor overconfidence and trading volume", Review of Financial Studies, vol. 19, no. 4, (2006), pp. 1531-1565.

[43] X. Luo, J. Zhang and W. Duan, "Social media and firm equity value", Information Systems Research, vol. 24, no. 1, (2013), pp. 146-163.

[44] X. Chen, "Blog as a communication tool", Proceedings of the 2009 Second International Conference on Future Information Technology and Management Engineering (FITME 2009), (2009), pp. 584-7.

[45] M. G. Dekimpe and D. M. Hanssens, "Sustained spending and persistent response: A new look at longterm marketing profitability", Journal of Marketing Research, (1999), pp. 397-412.

[46] J. D. Hamilton, "Time series analysis", Princeton university press Princeton, vol. 2, (1994).

[47] C. W. Granger, "Investigating causal relations by econometric models and cross-spectral methods", Econometrica: Journal of the Econometric Society, (1969), pp. 424-438.

[48] G. Gao and L. M. Hitt, "Information technology and trademarks: Implications for product variety", Management Science, vol. 58, no. 6, (2012), pp. 1211-1226.

[49] W. W. Moe and P. S. Fader, "Dynamic conversion behavior at e-commerce sites", Management Science, vol. 50, no. 3, (2004), pp. 326-335.

[50] C. Dellarocas, G. Gao and R. Narayan, "Are consumers more likely to contribute online reviews for hit or niche products?", Journal of Management Information Systems, vol. 27, no. 2, (2010), pp. 127-158.

[51] R. Aggarwal, "Putting money where the mouths are: The relation between venture financing and electronic word-rof-mouth". Information Systems Research, vol. 23, (3-part-2), (2012), pp. 976-992. 